\title{
MAPEAMENTO E DESENVOLVIMENTO DE COMPETENCIAS: UM ESTUDO DE CASO NOS CARGOS ADMINISTRATIVOS DO DEPARTAMENTO DE CULTURA E EVENTOS DA UFSC
}

\section{Competence mapping and development: $A$ case study with administrati-} ve positions at UFSC's Departmente of Culture and Events

\begin{abstract}
Monica Scoz Mendes
E-mail: monica.scoz@ufsc.br

Mestra em Administração Universitária pela Universidade Federal de Santa Catarina; Especialista em Gestão Empresarial pela Fundação Getúlio Vargas. endereço para contato: Campus Universitário Reitor João David Ferreira Lima, s/n, Trindade, 88040900, Florianópolis, Santa Catarina, Brasil. https://orcid.org/0000-0002-3671-385X
\end{abstract}

Gabriela Mattei de Souza E-mail: gabriela.mattei@ufsc.br Mestra em Engenharia e Gestão do Conhecimento pela Universidade Federal de Santa Catarina; Doutoranda em Administração pela Universidade Federal de Santa Catarina. https://orcid.org/0000-0002-3579-167X

Kelly Cristina Benetti Tonani Tosta E-mail: kellycbenetti@gmail.com

Doutora em Engenharia e Gestão do Conhecimento pela Universidade Federal de Santa Catarina; Mestra em Administração pela Universidade Federal de Santa Catarina. https://orcid.org/0000-0003-0531-5282

Marcos Baptista Lopez Dalmau E-mail: marcos.dalmau@ufsc.br Doutor em Engenharia de Produção pela Universidade Federal de Santa Catarina; Mestre em Engenharia de Produção pela Universidade Federal de Santa Catarina. https://orcid.org/0000-0002-8620-1625 


\section{Resumo}

O modelo de gerenciamento por competências visa ao fortalecimento da gestão e ao desenvolvimento dos seus recursos humanos. Neste artigo, verificou-se se as capacitações oferecidas pela UFSC relacionam-se com as competências requeridas aos cargos de Auxiliar em Administração, Assistente em Administração e Administrador do seu Departamento de Cultura e Eventos. Foram mapeadas as competências necessárias a cada cargo, assim como aquelas requeridas pelas atividades realizadas, mapeando o gap entre elas e então relacionando esse gap com as capacitações oferecidas pela UFSC. O presente artigo apresenta natureza aplicada, de abordagens qualitativa e descritiva, além de ser um estudo de caso. Para a coleta de dados, realizou-se pesquisa bibliográfica, além da pesquisa documental e entrevistas. Ao final deste estudo, evidenciou-se o relacionamento entre as capacitações oferecidas pela UFSC e as competências requeridas aos cargos, e foram identificadas e inventariadas as competências que ainda carecem de capacitações.

Palavras-chave: Competências. Mapeamento de competências. Desenvolvimento de competências. Gestão por competências.

\section{Abstract}

The model of competence management aims to strengthen administration and develop its human resources. In this article, it was verified if the trainings offered by UFSC relate to the competences required to the positions occupied by Administrator, Manager Assistant and Manager Auxiliary, all located within UFSC's Department of Culture and Events. The necessary competences were mapped to each position, as well as those required to the performed activities, mapping the gap between them and then, relating this gap to the trainings offered by the University. This present study has applied nature, with qualitative and descriptive approach, and is classified as a case study. To data collect, bibliographic research was used, as well as interviews and documental research. In the end, the relationship between offered trainings and the required competences to each position was evidenced and the competences that still need trainings were identified and inventoried.

Keywords: Competences. Competence mapping. Competence development. Competence management.

\section{INTRODUÇÃO}

A vida organizacional vem passando por transformações nas últimas décadas, tendo sido fortemente influenciada por uma nova mola propulsora da ordem econômica: o conhecimento. Nesse sentido, percebe-se que a antiga vida organizacional, baseada no capital e uso intensivo da mão de obra está desaparecendo rapidamente e somente as organizações capazes de desenvolver competências que seguem a nova lógica apresentarão maiores chances de continuar competindo (Tosta, 2011). Aliado a esse fato, Dalmau (2014) afirma que se pode perceber nas organizações uma crescente valorização das pessoas, evento que pode ser atribuído às mudanças constantes com as quais se deparam as organizações. Amaral (2008) destaca que, por conta dessas mudanças, o mundo do trabalho e, principalmente, do serviço público, vem passando por transformações recentemente, podendo-se observar, inclusive, reflexos na formação dos servidores, que passam a ter um perfil multifuncional, firmando-se 
enquanto detentores de conhecimentos técnicos, habilidades e atitudes relevantes para o desempenho de suas funções.

Nesse contexto, ganha força o modelo de gerenciamento por competência, que, segundo Belfort, Santos, e Tadeucci (2012), "é o modo de conduzir os colaboradores para atingirem os objetivos da organização por meio de suas capacidades técnicas e comportamentais, como opção aos padrões modernos de gestão" (p. 41). Esse modelo visa ao fortalecimento da gestão, fornecendo-lhe mais capacidade no planejamento, na captação e no desenvolvimento dos recursos humanos necessários à conquista de melhores resultados operacionais (Belfort et al., 2012). Sartoretto (2016) defende que o modelo de gestão por competências se apresenta com o propósito de alinhar a estratégia organizacional com as competências individuais de seus trabalhadores. Para Sartoretto, "gerar ou incorporar inovações não é uma necessidade apenas das organizações privadas; no serviço público, ainda mais do que na iniciativa privada, é necessário garantir que os resultados obtidos atendam às necessidades dos cidadãos" (p. 15).

Na Administração Pública Federal, a gestão por competências foi introduzida pelo Decreto 5.707 (2006), que instituiu a Política Nacional de Desenvolvimento de Pessoal, a ser implantada pelos órgãos da Administração Pública Federal. O Decreto em questão tem como finalidade a adequação das competências exigidas dos servidores aos objetivos das instituições e especifica novos métodos e técnicas de capacitação e desenvolvimento, o que se apresenta como um grande desafio à administração pública (Decreto 5.707, 2006a). Entretanto, apesar desse marco legal, Sartoretto (2016) afirma que, no serviço público, a gestão por competências ainda necessita de discussões mais aprofundadas.

Dessa forma e tomando por base a concepção de Eco (2014), em que a Universidade ainda é o lugar em que podem proliferar confrontos e discussões, ideias melhores por um mundo melhor, o reforço e a defesa de valores fundantes universais difundidos e propagados pelos meios os mais distintos, busca-se, neste trabalho, verificar se as capacitações oferecidas pela Universidade Federal de Santa Catarina (UFSC) possuem relação com as competências requeridas aos cargos de Administrador, Assistente em Administração e Auxiliar em Administração do seu Departamento de Cultura e Eventos (DCEven). À época da pesquisa, o referido Departamento contava com 20 servidores ativos.

Como forma de atingir esse objetivo, será necessário identificar e inventariar as competências necessárias a cada cargo, assim como aquelas requeridas para a realização das atividades específicas do setor. Após, serão verificadas as capacitações oferecidas pela UFSC para então constatar se essas capacitações se relacionam com o desenvolvimento das competências exigidas aos cargos.

Nesse contexto, vale ressaltar a justificativa deste estudo, que, de acordo com Roesch (2012), pode ser respaldada com ênfase na sua importância, oportunidade e viabilidade. A 
pesquisa é importante, tendo em vista que a implementação da gestão por competências no setor público tem se tornado uma realidade cada vez mais eminente, considerando principalmente a divulgação do Decreto 5.707 (2006), que institui a Política e as Diretrizes para o Desenvolvimento de Pessoal da Administração Pública Federal direta, autárquica e fundacional, tendo como uma de suas finalidades a adequação das competências requeridas dos servidores aos objetivos das instituições, tendo como referência o plano plurianual (Decreto 5.707, 2006a).

Além disso, o presente estudo mostra-se oportuno, já que se realiza em um momento propício na UFSC, visto que o desenvolvimento de seus servidores é uma meta da sua gestão (Universidade Federal de Santa Catarina [UFSC], 2016b). Ampliando a discussão, podese perceber que a oportunidade se caracteriza também na medida em que este trabalho pretende contribuir com a política de gestão de pessoas da própria UFSC, esperando trazer à tona evidências que proporcionem sua efetiva melhoria e colaborem com a captação e o desenvolvimento das pessoas. Por fim, há viabilidade de tempo para a realização da pesquisa, considerando o escopo proposto, e também viabilidade financeira, haja vista o acesso dos pesquisadores ao material, tanto bibliográfico quanto de conteúdo prático.

\section{DESENVOLVIMENTO TEÓRICO}

\subsection{COMPETÊNCIA E GESTÃO POR COMPETÊNCIAS}

Ao longo dos tempos, tem-se observado uma tendência da área de gestão de pessoas das organizações em voltar-se ao desenvolvimento de habilidades e autoconfiança de seus servidores, características essas necessárias para o ambiente de constante mutação onde estão inseridas (Kwasnicka, 2007). Ao colocarem em prática o patrimônio de conhecimento da organização, as pessoas concretizam as competências organizacionais e as adaptam ao contexto onde estão inseridas, utilizando tal conhecimento de maneira consciente a fim de conferir validade e implementar modificações para aprimorá-lo, sendo, portanto, conforme Dutra (2001), essa "agregação de valor dos indivíduos [. . .] sua contribuição efetiva ao patrimônio de conhecimentos da organização, o que the permite manter suas vantagens competitivas ao longo do tempo" (p. 25).

Para que sejam bem-sucedidas, as organizações devem alinhar as pessoas às suas estratégias, sendo, assim, necessário um planejamento eficiente tanto para assegurar que existam pessoas disponíveis para a realização desses objetivos quanto que estas sejam competentes para tal (Bateman, Thomas, \& Snell, 2011). Assim, com o intuito de manter as pessoas motivadas e com condições de demonstrarem competência no desempenho de 
suas atividades, Grillo (2001) destaca que devem ser realizadas atividades motivadoras dentro do âmbito da administração pública, considerando as restrições legais referentes à remuneração existentes nesse setor.

Diante dessa conjuntura, destaca-se ainda que o modelo de gestão por competências, proposta a ser utilizada no presente artigo, deve considerar as peculiaridades de cada organização, uma vez que, para Amaral (2008), o referido modelo visa a "atender também os objetivos institucionais, assegurar o alinhamento do modelo com a cultura e orientações estratégicas, garantir flexibilidade diante de mudanças e estimular um ambiente de autodesenvolvimento, trabalho participativo e multifuncionalidade" (p. 12).

Sobre as competências, Moura (2009) expõe que elas vêm sendo utilizadas como ferramentas de negócios desde o início dos anos 1980, tornando-se elemento essencial nas estratégias organizacionais, destacando ainda pesquisas que demonstram uma forte relação entre desempenho e desenvolvimento de competências nas pessoas. $O$ modelo de gestão por competências é relativamente novo e complexo, o que contribui para diversas incertezas com relação ao setor público; no entanto, os resultados obtidos no setor privado têm servido de inspiração, ressaltando-se a preocupação com a adaptabilidade do privado para o público, em razão da diferente lógica aplicada nesses diferentes âmbitos (Amaral, 2008).

Ademais, Dutra (2001) complementa que "o uso do conceito de competência também permitiu o surgimento de uma gestão de pessoas mais alinhada com as expectativas e as necessidades das organizações e dos indivíduos" (p. 39). A noção de competências, então, aparece associada a verbos como saber, agir, mobilizar recursos, integrar saberes, saber aprender, assumir responsabilidades, ter visão estratégica, além de ser ligada ao conceito de conhecimento, habilidades e atitudes com o intuito de agregar valor econômico e social (Gomes, 2008; Fleury \& Fleury, 2001). Ainda, os autores expõem a existência de diferentes tipos de competências, sendo elas, em um nível mais geral, as competências organizacionais e as próprias competências individuais, destacando-se a importância da inter-relação entre os níveis de competência para que seja possível o mapeamento de recursos, a análise do ambiente e a realização de escolhas estratégicas para a organização.

O processo de inventário dessas competências recebe o nome de mapeamento e tem por objetivo identificar, sistematizar e evidenciar as competências da organização e de seus colaboradores. É a partir desse mapeamento que se identificam os pontos fortes $e$ as lacunas de competências organizacionais e individuais, permitindo ao gestor alocar adequadamente os colaboradores, identificar suas potencialidades e carências e, ainda, selecionar e desenvolver as competências necessárias ao desempenho estratégico da organização (Torres, Ziviani, \& Silva, 2012).

Por fim, no âmbito da gestão por competências, Torres et al. (2012) destacam a ambiguidade existente entre a necessidade da área de gestão de pessoas em assumir papel 
no desenvolvimento das estratégias organizacionais e a necessidade de manter e desenvolver competências necessárias para realizar os objetivos da empresa, sendo, portanto, necessário organizar a relação entre as competências organizacionais e individuais, a partir do seu mapeamento, a fim de garantir que o processo de desenvolvimento de competências agregue valor para ambos os envolvidos-instituição e servidor.

\subsection{COMPETÊNCIAS REQUERIDAS AOS CARGOS}

Historicamente, os cargos representam uma forma de mediação e troca de incentivos entre as empresas e os indivíduos em que, de um lado, encontram-se as expectativas, necessidades e recursos pessoais (conhecimentos, habilidades e aptidões humanas) e, de outro, os objetivos, missão e necessidades da organização (Moraes, 2004). A análise de cargos é um processo que visa justamente a definir os comportamentos necessários para a realização de determinadas atividades, identificando conhecimentos, habilidades e aptidões necessárias para o desempenho das suas atividades (Robbins, 2000).

No entanto, diversas organizações vêm adotando não somente esse modelo de descrição de cargos como estrutura básica para gestão de pessoas, mudando o foco, então, para o indivíduo, voltando novamente ao cerne do conceito de competência, no qual, conforme Fleury e Fleury (2001), "todo o processo de desenvolvimento das pessoas deve estar alinhado à definição de estratégias de negócios competências essenciais da organização" (p. 193).

Dessa forma, Moraes (2004) explica que "a estrutura de cargos é elaborada para atender à estratégia empresarial da melhor forma possível. O desenho de um cargo é o processo de criar e definir tarefas específicas do indivíduo que irá ocupá-lo" (p. 221). Internacionalmente, os cargos, em sua grande maioria, têm suas atividades descritas por meio do Dictionary of Occupational Titles (Dicionário de Títulos Ocupacionais), ou simplesmente CBO, descrição compilada pelo Ministério do Trabalho dos Estados Unidos, contendo uma padronização de cerca de 20 mil cargos, com o objetivo de realizar estruturações classificatórias sistemáticas baseadas na inter-relação entre as tarefas e requisitos das ocupações, contribuindo, assim, para uma maior uniformidade nas diferentes regiões daquele País (Snell \& Bohlander, 2009).

No Brasil, considerando o escopo de estudo do presente artigo, pode-se destacar a existência da Lei 11.091 (2005), que dispõe sobre a estruturação do Plano de Carreira dos Cargos Técnico-administrativos em Educação, no âmbito das Instituições Federais de Ensino vinculadas ao Ministério da Educação, como é o caso da Universidade Federal de Santa Catarina (Lei 11.091, 2005). Os cargos citados na referida lei foram descritos detalhadamente por meio do Ofício Circular 015/2005/CGGP/SAA/SE/MEC (2005), publicado com o mesmo intuito de uniformizar os cargos existentes para a realização de concurso público na área de Técnico-administrativos em Educação no País (Ofício Circular 015/2005/CGGP/SAA/ SE/ 
MEC (2005)), ofício este vigente à época em que os dados foram coletados para a presente pesquisa.

\subsection{A UFSC E O CENTRO DE CULTURA E EVENTOS}

A Universidade Federal de Santa Catarina (UFSC), fundada em 18 de dezembro de 1960, com sede em Florianópolis, conta hoje com quatro campi em diferentes cidades do Estado-Araranguá, Blumenau, Curitibanos e Joinville. Com o objetivo de promover o ensino, a pesquisa e a extensão, engloba uma comunidade de mais de 50 mil pessoas, entre servidores e estudantes, realizando diversas formas de cooperação com instituições de ensino ao redor do mundo, atualmente contando com cerca de 300 convênios com mais de 40 países (UFSC, $2016 \mathrm{~b}$ ).

Com mais de 30 mil estudantes em mais de 100 cursos de graduação, necessita de um grande aparato e estrutura para realizar formaturas e demais eventos, tanto acadêmicos quanto culturais. Para tal, conta com a Secretaria de Cultura e Arte (SecArte), órgão da administração central "responsável pelo fomento e desenvolvimento da cultura e arte na Universidade Federal de Santa Catarina" (UFSC, 2016a). Essa Secretaria foi criada em 2008 e possui, hoje, além de sua administração central, o Departamento Artístico Cultural (DAC), o Núcleo de Estudos Açorianos (NEA), a Coordenadoria das Fortalezas da llha de Santa Catarina, e o Departamento de Cultura e Eventos (DCEven) (UFSC, 2016a), esse último foco de estudos do presente artigo, cujo objetivo principal é planejar, desenvolver e gerenciar as atividades do DCEven da UFSC (UFSC, 2016d). Esse departamento é composto por três coordenadorias: Espaço Físico e Logística (INFGRALOG), Audiovisual e Eventos, que realizam, conjuntamente, cerca de 300 eventos ao ano (UFSC, 2016a), o que evidencia a importância da capacitação dos seus servidores.

\section{PROCEDIMENTOS METODOLÓGICOS}

O presente artigo apresenta natureza aplicada, considerando que é o tipo de pesquisa, segundo Ruiz (2002), que "toma certas leis ou teorias mais amplas como ponto de partida, e tem por objetivo investigar, comprovar ou rejeitar hipóteses sugeridas pelos modelos teóricos" (p. 50). A abordagem utilizada foi qualitativa, exposta por Minayo (2001) como o tipo de pesquisa que responde a questões participativas, principalmente nas ciências sociais, em que o nível de realidade não pode ser quantificado, abordando um "universo de significados, motivos, aspirações, crenças, valores e atitudes, o que corresponde a um espaço mais profundo das relações dos processos e dos fenômenos que não podem ser reduzidos à 
operacionalização de variáveis" (pp. 21-22). Ademais, a pesquisa é considerada descritiva, pois, segundo Cervo, Bervian, e Silva (2007), é aquela que aborda "dados e problemas que merecem ser estudados, mas cujo registro não consta de documentos" (p. 62). Como método, utilizou-se o estudo de caso, que, para Gil (2007), é um "estudo aprofundado e exaustivo de um ou poucos objetos, de maneira que permita seu amplo e detalhado conhecimento" ( $p$. 54), além de ser uma forma de análise profunda de um ou poucos fatos com a finalidade de obter grande detalhamento do objeto estudado (Santos, 2010).

Para a coleta de dados, foi realizada pesquisa bibliográfica para o embasamento teórico, explicada por Cervo e Bervian (1983) como aquela que busca "conhecer e analisar as contribuições culturais ou científicas do passado existentes sobre determinado assunto, tema ou problema" (p. 55). Além disso, foi realizada pesquisa documental, que pode ser diferenciada da pesquisa bibliográfica pela natureza das suas fontes, conforme Gil (2010) valendo-se "de toda sorte de documentos, elaborados com finalidades diversas" (p. 30). Por fim, para a coleta de dados referentes às atividades existentes no escopo do estudo, primeiramente, realizou-se uma comparação entre as competências já expressas nas atribuições dos cargos (Decreto 5.825, 2006b) e aquelas determinadas pelo Departamento de Cultura e Eventos, explicitadas em documento próprio elaborado em conjunto com os coordenadores das três Coordenadorias de Audiovisual, de Eventos e de Infraestrutura e Logística, por ocasião da elaboração do seu regimento interno, durante a Gestão de 2012 a 2016.

Em um segundo momento, foram realizadas, no mês de dezembro de 2016, três entrevistas semiestruturadas: com a Diretoria do DCEven/UFSC, com a Coordenadoria de Eventos do DCEven e com a Coordenadoria de Capacitação de Pessoas da Pró-reitoria de Desenvolvimento e Gestão de Pessoas da UFSC. Para compreensão do teor dos dados coletados, optou-se por realizar a análise de conteúdo das respostas. As duas primeiras entrevistas possibilitaram ratificar as informações expostas no documento analisado na primeira etapa deste estudo, na medida em que comprovaram as atividades desempenhadas pelos servidores ocupantes dos três cargos analisados. Além disso, a primeira entrevista, realizada com a Diretoria do DCEven, permitiu identificar quais conhecimentos, habilidades e atitudes se relacionam com cada uma das atribuições listadas para os cargos. Na terceira entrevista, foi possível relacionar os cursos oferecidos pela Coordenadoria de Capacitação de Pessoas com as competências requeridas aos três cargos aqui estudados. 


\section{RESULTADOS}

\subsection{MAPEAMENTO DAS COMPETÊNCIAS}

Com o intuito de reduzir o escopo de estudo, optou-se por analisar as atividades realizadas por ocupantes dos três cargos administrativos existentes hoje na UFSC: Administrador, Assistente em Administração e Auxiliar em Administração. Tendo por base uma análise do Ofício Circular 015/2005/CGGP/SAA/SE/MEC-vigente à época da pesquisa-que detalha os cargos técnico-administrativos em educação autorizados pelo Ministério de Planejamento, Orçamento e Gestão para concurso público e também por meio de documento interno do DCEven, pode-se chegar a uma comparação entre aquilo que é requerido aos ocupantes dos cargos e as competências efetivamente requeridas na prática do seu exercício profissional (Ofício Circular 015/2005/CGGP/SAA/SE/MEC, 2005). Para facilitar a visualização das informações, são apresentadas à esquerda as competências legais, obtidas da descrição do cargo, em comparativo com as competências efetivamente executadas pelos ocupantes dos cargos à sua direita, conforme se pode observar nas Tabelas 1,2 e 3. Estas serão apresentadas em sequência com comentários ao final por se entender que, embora as competências sejam diferentes, a análise pode ser feita de forma conjunta.

Tabela 1

Competências legais versus Competências requeridas-cargo Administrador

\begin{tabular}{ll}
\hline \multicolumn{1}{c}{ Competências legais } & \multicolumn{1}{c}{ Competências requeridas } \\
\hline & a) Atender e orientar o público; \\
& b) Organizar e distribuir os períodos de realização das formaturas a serem \\
utilizados pelas unidades de ensino; & c) Instruir equipes de apoio nos cerimoniais de eventos; \\
& d) Coordenar a entrega de becas nas formaturas; \\
Administrar organizações & e) Organizar e coordenar eventos acadêmicos da UFSC; \\
& f) Manter contato com as unidades administrativas pertinentes às colações \\
de grau e comissões de formaturas; & g) Assessorar as unidades acadêmicas e administrativas com relação aos \\
& protocolos do cerimonial universitário.
\end{tabular}

a) Reunir informações para relatórios;

Elaborar planejamento organi- b) Conferir junto ao Departamento de Administração Escolar (DAE) e à zacional

Pró-reitoria de Graduação (Prograd) o calendário acadêmico;

c) Elaborar e publicar no site os calendários de colações de grau da UFSC.

Implementar programas e projetos

Controlar e acompanhar pregões.

Promover estudos de racionalização

Não foram relacionadas atribuições práticas.

Realizar controle do desempenho organizacional

Acompanhar arrecadação e gastos do Departamento.

Prestar consultoria administrativa

Elaborar termos de referência para licitações. 


\section{Competências legais}

Competências requeridas

Utilizar recursos de informática

Executar tarefas de mesma natureza e nível de complexidade associadas ao ambiente organizacional
Neste estudo, essas atribuições foram consideradas amplas e de uso geral do servidor, sendo partes integrantes das demais atribuições.

\section{Tabela 2}

Competências legais versus Competências requeridas-cargo Assistente em Administração

Competências legais Competências requeridas

$\begin{array}{ll}\text { Tratar documentos } & \text { a) Organizar a agenda da Direção; } \\ & \text { b) Elaborar e controlar correspondências físicas e digitais; } \\ & \text { c) Receber e arquivar documentos diversos utilizados pelo setor. }\end{array}$

Preparar relatórios, formulários a) Gerar relatório de atividades;

e planilhas b) Elaborar formulários pertinentes ao setor.

Acompanhar processos admi- a) Coordenar a comunicação interna; nistrativos b) Apresentar quadros de energia.

a) Atender e orientar o público;

b) Acompanhar a montagem, realização e desmontagem dos eventos;

c) Mostrar as saídas de emergência;

d) Apresentar local de retirada das mesas, biombos, suporte, entre outros;

Atender usuários no local ou à

e) Coordenar a entrega de becas;

distância

f) Manter contato com as unidades administrativas pertinentes às colações de grau e comissões de formaturas;

g) Assessorar as unidades acadêmicas e administrativas com relação aos protocolos do cerimonial universitário;

h) Supervisionar as atividades dos terceirizados que atendem o DCEven.

a) Registrar e controlar as férias dos servidores;

b) Atender a demandas emergenciais;

Dar suporte administrativo e

c) Elaborar relatório de frequência dos terceirizados e funcionários cedidos; técnico na área de recursos

d) Agendar reunião com os organizadores dos eventos; humanos

e) Orientar quanto às responsabilidades durante o evento;

f) Instruir equipes de apoio nos cerimoniais;

g) Sugerir quantitativo de pessoal de apoio e de material de limpeza.

a) Assessorar a direção do DCEven nas suas demandas e atendimentos;

b) Controlar e acompanhar pregões;

c) Orientar, disponibilizar e fiscalizar o uso dos espaços e materiais para e durante os eventos;

d) Auxiliar na execução dos termos de permissão dos espaços;

e) Liberar estacionamento para equipes de apoio ao evento, assim como acesso ao prédio nos finais de semana e uso das chaves;

Dar suporte administrativo e técnico na área de materiais, patrimônio e logística

f) Observar as atividades dos prestadores de serviço, assim como equipe de limpeza e segurança;

g) Dispor acesso de internet durante o evento;

h) Com o responsável do setor de audiovisual, apresentar informações referentes à infraestrutura, escala dos técnicos de som, segurança e limpeza;

i) Acompanhar a manutenção das becas, capelos, entre outros itens que atendam ao cerimonial universitário;

j) Acompanhar a manutenção do patrimônio físico;

k) Elaborar e monitorar inventário patrimonial;

l) Solicitar e controlar material de almoxarifado e expediente.

Dar suporte administrativo e técnico na área orçamentária e financeira a) Auxiliar na elaboração de termos de referência para licitações;

b) Com o responsável do setor de audiovisual, apresentar informações referentes à emissão e controle de pagamento do Guia de Recolhimento de União (GRU) e a planilhas de custo. 
Participar da elaboração de projetos referentes à melhoria dos serviços da Insti-

Não foram relacionadas atribuições práticas. tuição

Coletar dados; elaborar planiIhas de cálculos; confeccionar organogramas, fluxogramas e cronogramas; atualizar dados para a elaboração de planos e projetos

\begin{tabular}{ll}
\hline $\begin{array}{l}\text { Secretariar reuniões e outros } \\
\text { eventos }\end{array}$ & Secretariar reuniões do Departamento. \\
\hline $\begin{array}{l}\text { Redigir documentos utilizando } \\
\text { redação oficial }\end{array}$ & Redigir documentos utilizando redação oficial. \\
\hline Digitar documentos & Digitar documentos. \\
\hline Utilizar recursos de informática & Gerenciar e atualizar o site. \\
\hline
\end{tabular}

Executar tarefas de mesma natureza e nível de complexidade associadas ao ambiente organizacional
Não foram relacionadas atribuições práticas.

Neste estudo, essa atribuição foi considerada ampla e de uso geral do servidor, sendo parte integrante das demais atribuições.

Tabela 3

Competências legais versus Competências requeridas-cargo Auxiliar em Administração

\section{Competências legais}

Assistir à Direção do órgão

\section{Competências requeridas}

a) Organizar agenda da Direção;

b) Atender a demandas emergenciais;

c) Manter contato com as unidades administrativas pertinentes às colações de grau e comissões de formatura.

a) Registrar e controlar as férias dos servidores;

b) Secretariar reuniões do Departamento;

c) Elaborar relatório de frequência dos terceirizados e funcionários cedidos;

d) Orientar, disponibilizar e fiscalizar o uso dos espaços e materiais para e durante os eventos;

e) Dispor acesso de internet durante o evento;

f) Colocar os avisos de "Reservado" nos assentos do auditório;

g) Com o responsável do setor de audiovisual, apresentar informações re-

Organizar e executar atividades administrativas em suas diversas áreas ferentes à infraestrutura, escala dos técnicos de som, segurança e limpeza, assim como informações referentes à emissão e controle de pagamento do GRU e a planilhas de custo;

h) Assessorar as unidades acadêmicas e administrativas com relação aos protocolos e normas a serem respeitados no cerimonial universitário:

i) Coordenar a manutenção das becas, capelos, entre outros itens que atendam ao cerimonial universitário;

j) Liberar estacionamento para equipes de apoio ao evento, assim como acesso ao prédio nos finais de semana e uso das chaves;

k) Observar as atividades dos prestadores de serviço, assim como equipe de limpeza e segurança. 


\begin{tabular}{|c|c|}
\hline $\begin{array}{l}\text { Atender usuários e tratar de } \\
\text { documentos e atos administra- } \\
\text { tivos }\end{array}$ & $\begin{array}{l}\text { a) Atender e orientar o público; } \\
\text { b) Reunir informações para relatórios; } \\
\text { c) Coordenar a comunicação interna; } \\
\text { d) Receber e arquivar documentos diversos utilizados pelo setor; } \\
\text { e) Coordenar manutenção do patrimônio físico; } \\
\text { f) Instruir equipes de apoio nos cerimoniais; } \\
\text { g) Coordenar e entregar becas; } \\
\text { h) Realizar credenciamento de fotógrafos e cinegrafistas; } \\
\text { i) Coordenar o empréstimo de materiais relativo a eventos; } \\
\text { j) Receber, orientar e encaminhar à Secretaria de Cultura o termo de per- } \\
\text { missão de uso dos espaços. }\end{array}$ \\
\hline $\begin{array}{l}\text { Assessorar nas atividades de } \\
\text { ensino, pesquisa e extensão }\end{array}$ & Não foram relacionadas atribuições práticas. \\
\hline $\begin{array}{l}\text { Executar serviços de apoio nas } \\
\text { diversas áreas administrativas }\end{array}$ & $\begin{array}{l}\text { a) Auxiliar na execução dos termos de permissão dos espaços; } \\
\text { b) Organizar e coordenar eventos acadêmicos da UFSC; } \\
\text { c) Gerar relatórios de atividades; } \\
\text { d) Elaborar formulários pertinentes ao setor; } \\
\text { e) Elaborar e monitorar inventário patrimonial; } \\
\text { f) Solicitar e controlar material de almoxarifado e expediente. }\end{array}$ \\
\hline $\begin{array}{l}\text { Utilizar recursos de informá- } \\
\text { tica; }\end{array}$ & $\begin{array}{l}\text { a) Gerenciar e atualizar de site; } \\
\text { b) Gerar e confirmar pagamento de GRUs. }\end{array}$ \\
\hline
\end{tabular}

Executar tarefas de mesma natureza e nível de complexidade associadas ao ambiente organizacional

Nota. Nas entrevistas não foram atribuídas atividades com relação direta às competências legais, extraídas do Ofício Circular 015/2005/CGGP/SAA/SE/MEC.

Com essa análise comparativa das competências legais e requeridas, é possível identificar algumas competências exigidas na prática que vão além daquilo que é exigido ao cargo. Assim, podem-se destacar algumas competências necessárias aos servidores que vão desempenhar tais atividades, como se apresenta nas Tabelas 4, 5 e 6. Ressalta-se, aqui, que se optou por elencar as cinco principais competências de cada cargo levando em consideração as especificidades relacionadas aos eventos e cerimoniais vivenciados pelos servidores, com o intuito de aprofundar a análise e também melhor embasar a relação com as capacitações existentes. As Tabelas serão apresentadas em sequência com comentários ao final por se entender que, embora as competências, conhecimentos, habilidades e atitudes sejam diferentes, a análise pode ser feita de forma conjunta.

Tabela 4

Competências requeridas ao cargo de Administrador no DCEven

\begin{tabular}{clll}
\hline \multicolumn{1}{c}{ COMPETÊNCIA } & \multicolumn{1}{c}{ CONHECIMENTO } & \multicolumn{1}{c}{ HABILIDADE } & \multicolumn{1}{c}{ ATITUDE } \\
\hline & - rotinas das cerimônias; & - usar equipamento de pro- & \\
& - Resolução Normativa 31/ & jeção; & - ser solícito; \\
Instruir equipes de apoio & CGRAD/2016; & - dar feedback; & - empatia com as \\
nos cerimoniais & - Portarias de Colação de & - boa comunicação verbal; & pessoas; \\
& Grau emitidas pela PRO- & - flexibilidade; & - concentração. \\
& GRAD anualmente. & - ser multitarefas. & \\
\hline
\end{tabular}




\begin{tabular}{|c|c|c|c|}
\hline COMPETÊNCIA & CONHECIMENTO & HABILIDADE & ATITUDE \\
\hline $\begin{array}{l}\text { Assessorar as unidades } \\
\text { acadêmicas e adminis- } \\
\text { trativas com relação aos } \\
\text { protocolos do cerimonial } \\
\text { universitário }\end{array}$ & $\begin{array}{l}\text { - protocolos a serem respei- } \\
\text { tados de cerimonial univer- } \\
\text { sitário; } \\
\text { - Resolução Normativa 31/ } \\
\text { CGRAD (2016); } \\
\text { - rotinas das cerimônias. }\end{array}$ & $\begin{array}{l}\text { - boa comunicação verbal; } \\
\text { - saber lidar com pessoas. }\end{array}$ & $\begin{array}{l}\text { - proatividade; } \\
\text { - receptividade; } \\
\text { - acolhimento. }\end{array}$ \\
\hline $\begin{array}{l}\text { Controlar e acompanhar } \\
\text { pregões }\end{array}$ & $\begin{array}{l}\text { - Lei } 8.666(1990) ; \\
\text { - Lei } 10.520(2002) \text {; } \\
\text { - Sistema de pregão eletrôni- } \\
\text { co na UFSC. }\end{array}$ & $\begin{array}{l}\text { - planejamento; } \\
\text { - organização. }\end{array}$ & $\begin{array}{l}\text { - proatividade; } \\
\text { - concentração. }\end{array}$ \\
\hline $\begin{array}{l}\text { Acompanhar arrecada- } \\
\text { ção e gastos do Departa- } \\
\text { mento }\end{array}$ & $\begin{array}{l}\text { - Lei } 4.320(1964) \\
\text { - contabilidade básica. }\end{array}$ & $\begin{array}{l}\text { - ter facilidade com números; } \\
\text { - ter bom raciocínio. }\end{array}$ & $\begin{array}{l}\text { - concentração; } \\
\text { - ética. }\end{array}$ \\
\hline $\begin{array}{l}\text { Elaborar termos de refe- } \\
\text { rência para licitações }\end{array}$ & $\begin{array}{l}\text { - Lei } 8.666 \text { (1990); } \\
\text { - funcionamento das licita- } \\
\text { ções na UFSC. }\end{array}$ & - boa comunicação escrita. & - concentração. \\
\hline
\end{tabular}

Tabela 5

Competências requeridas ao cargo de Assistente em Administração no DCEven

\begin{tabular}{|c|c|c|c|}
\hline COMPETÊNCIA & CONHECIMENTO & HABILIDADE & ATITUDE \\
\hline $\begin{array}{l}\text { Atender e orientar o } \\
\text { público }\end{array}$ & $\begin{array}{l}\text { - qual o perfil do público; } \\
\text { - quais as necessidades } \\
\text { do público. }\end{array}$ & $\begin{array}{l}\text { - saber lidar com pessoas; } \\
\text { - boa comunicação } \\
\text { verbal. }\end{array}$ & $\begin{array}{l}\text { - receptividade; } \\
\text { - simpatia; } \\
\text { - acolhimento; } \\
\text { - calma; } \\
\text { - paciência; } \\
\text { - gentileza; } \\
\text { - cordialidade. }\end{array}$ \\
\hline $\begin{array}{l}\text { Supervisionar as ativida- } \\
\text { des dos terceirizados que } \\
\text { atendem ao DCEven }\end{array}$ & $\begin{array}{l}\text { - quais as atividades dos } \\
\text { terceirizados; } \\
\text { - responsabilidades dos } \\
\text { terceirizados; } \\
\text { - quem são os prepostos. }\end{array}$ & $\begin{array}{l}\text { - liderança; } \\
\text { - delegação de tarefas; } \\
\text { - motivar equipe; } \\
\text { - saber negociar. }\end{array}$ & $\begin{array}{l}\text { - proatividade; } \\
\text { - controle; } \\
\text { - tomada de decisão. }\end{array}$ \\
\hline $\begin{array}{l}\text { Gerenciar e atualizar o } \\
\text { site }\end{array}$ & $\begin{array}{l}\text { - Wordpress; } \\
\text { - Português; } \\
\text { - Redação Oficial. }\end{array}$ & $\begin{array}{l}\text { - manusear recursos de } \\
\text { informática. }\end{array}$ & $\begin{array}{l}\text { - agilidade; } \\
\text { - proatividade. }\end{array}$ \\
\hline $\begin{array}{l}\text { Sugerir quantitativo de } \\
\text { pessoal de apoio e de } \\
\text { material de limpeza }\end{array}$ & $\begin{array}{l}\text { - quantidade de pessoal } \\
\text { necessário para o evento; } \\
\text { - quantidade de material } \\
\text { necessário para o evento; } \\
\text { - quem é o fornecedor; } \\
\text { - cronograma de pedidos. }\end{array}$ & $\begin{array}{l}\text { - fazer cálculos; } \\
\text { - planejamento. }\end{array}$ & $\begin{array}{l}\text { - agilidade; } \\
\text { - concentração. }\end{array}$ \\
\hline $\begin{array}{l}\text { Organizar e coordenar } \\
\text { eventos acadêmicos da } \\
\text { UFSC }\end{array}$ & $\begin{array}{l}\text { - qual é o evento; } \\
\text { - quem é a equipe que } \\
\text { trabalhará no evento; } \\
\text { - quais serão os materiais } \\
\text { necessários; } \\
\text { - Português; } \\
\text { - rotinas do evento. }\end{array}$ & $\begin{array}{l}\text { - saber lidar com pessoas; } \\
\text { - liderança; } \\
\text { - delegação de tarefas; } \\
\text { - motivar equipe; } \\
\text { - flexibilidade; } \\
\text { - saber negociar; } \\
\text { - planejamento. }\end{array}$ & $\begin{array}{l}\text { - receptividade; } \\
\text { - simpatia; } \\
\text { - acolhimento; } \\
\text { - calma; } \\
\text { - paciência; } \\
\text { - gentileza; } \\
\text { - proatividade; } \\
\text { - controle. }\end{array}$ \\
\hline
\end{tabular}


Tabela 6

Competências requeridas ao cargo de Auxiliar em Administração no DCEven

\begin{tabular}{|c|c|c|c|}
\hline COMPETÊNCIA & CONHECIMENTO & HABILIDADE & ATITUDE \\
\hline $\begin{array}{l}\text { Secretariar reuniões do } \\
\text { Departamento }\end{array}$ & $\begin{array}{l}\text { - secretaria de reunião; } \\
\text { - preenchimento de atas; } \\
\text { - Redação Oficial; } \\
\text { - Português. }\end{array}$ & $\begin{array}{l}\text { - saber lidar com pessoas; } \\
\text { - organização de ideias; } \\
\text { - poder de síntese; } \\
\text { - boa comunicação escrita. }\end{array}$ & $\begin{array}{l}\text { - receptividade; } \\
\text { - simpatia; } \\
\text { - acolhimento; } \\
\text { - calma; } \\
\text { - paciência; } \\
\text { - gentileza; } \\
\text { - cordialidade; } \\
\text { - proatividade; } \\
\text { - controle. }\end{array}$ \\
\hline $\begin{array}{l}\text { Coordenar e entregar } \\
\text { becas }\end{array}$ & $\begin{array}{l}\text { - horários de entrega; } \\
\text { - público que irá receber as } \\
\text { becas; } \\
\text { - local onde serão entregues; } \\
\text { - equipe que irá trabalhar. }\end{array}$ & $\begin{array}{l}\text { - saber lidar com pessoas; } \\
\text { - organização do espaço; } \\
\text { - organização do tempo; } \\
\text { - manusear as becas (dobra- } \\
\text { dura, armazenamento). }\end{array}$ & $\begin{array}{l}\text { - receptividade; } \\
\text { - simpatia; } \\
\text { - acolhimento; } \\
\text { - calma; } \\
\text { - paciência; } \\
\text { - gentileza; } \\
\text { - proatividade; } \\
\text { - controle. }\end{array}$ \\
\hline $\begin{array}{l}\text { Realizar credenciamento } \\
\text { de fotógrafos e cinegra- } \\
\text { fistas }\end{array}$ & $\begin{array}{l}\text { - regulamento para profis- } \\
\text { sionais e empresas de foto e } \\
\text { filmagem; } \\
\text { - quem pode se credenciar; } \\
\text { - local, data e horário para } \\
\text { credenciamento; } \\
\text { - documentos necessários. }\end{array}$ & $\begin{array}{l}\text { - saber lidar com pessoas; } \\
\text { - organização do espaço; } \\
\text { - organização do tempo. }\end{array}$ & $\begin{array}{l}\text { - receptividade; } \\
\text { - simpatia; } \\
\text { - acolhimento; } \\
\text { - calma; } \\
\text { - paciência; } \\
\text { - gentileza; } \\
\text { - proatividade; } \\
\text { - controle. }\end{array}$ \\
\hline $\begin{array}{l}\text { Solicitar e controlar ma- } \\
\text { terial de almoxarifado e } \\
\text { expediente }\end{array}$ & $\begin{array}{l}\text { - materiais necessários; } \\
\text { - como solicitar o material; } \\
\text { - local de armazenamento. }\end{array}$ & $\begin{array}{l}\text { - organização do espaço; } \\
\text { - organização do tempo; } \\
\text { - planejamento. }\end{array}$ & $\begin{array}{l}\text { - calma; } \\
\text { - paciência; } \\
\text { - gentileza; } \\
\text { - proatividade; } \\
\text { - controle. }\end{array}$ \\
\hline $\begin{array}{l}\text { Coordenar a manutenção } \\
\text { das becas, capelos, entre } \\
\text { outros itens, que atendam } \\
\text { ao cerimonial universi- } \\
\text { tário }\end{array}$ & $\begin{array}{l}\text { - itens que atendem ao ceri- } \\
\text { monial universitário; } \\
\text { - como realizar a manuten- } \\
\text { ção; } \\
\text { - quem realiza a manuten- } \\
\text { ção. }\end{array}$ & $\begin{array}{l}\text { - saber lidar com pessoas; } \\
\text { - organização do espaço; } \\
\text { - organização do tempo; } \\
\text { - planejamento. }\end{array}$ & - controle. \\
\hline $\begin{array}{l}\text { Dispor acesso de internet } \\
\text { durante o evento }\end{array}$ & $\begin{array}{l}\text { - como dispor de acesso à } \\
\text { internet; } \\
\text { - quem libera o acesso; } \\
\text { - quem pode ter acesso à } \\
\text { internet. }\end{array}$ & - saber acessar a internet. & $\begin{array}{l}\text { - pró-atividade; } \\
\text { - controle. }\end{array}$ \\
\hline
\end{tabular}

Conforme exposto nas Tabelas 4, 5 e 6, pode-se observar os conhecimentos, habilidades e atitudes decorrentes das competências requeridas aos servidores ocupantes dos três cargos que atuam no DCEven. Com essa análise, partiu-se para a pesquisa relativa aos cursos de capacitação oferecidos pela UFSC com o intuito de comparar se há relação entre o que está sendo oferecido de capacitação e o que é requerido aos servidores do DCEven, tendo em vista tais competências não serem exigidas destes ao realizarem o concurso público, mas apenas quando da realização de suas atividades na prática em razão da peculiaridade das atividades realizadas por esse Departamento. 


\subsection{DESENVOLVIMENTO DE COMPETÊNCIAS: CAPACITAÇÕES NA UFSC}

Considerando a estrutura atual da UFSC, o setor responsável pelas capacitações dos servidores e, consequentemente, o desenvolvimento das suas competências, é a Coordenadoria de Capacitação de Pessoas (CCP), ligada ao Departamento de Desenvolvimento de Pessoas (DDP) da Pró-reitoria de Desenvolvimento e Gestão de Pessoas (Prodegesp). Para os objetivos do presente trabalho, foram analisadas as informações contidas no Plano Anual de Capacitação - Edição 2016 (UFSC, 2016c). Segundo o referido Plano (UFSC, 2016c, p. 29), capacitação pode ser conceituada como um "processo permanente e deliberado de aprendizagem, que utiliza ações de aperfeiçoamento e qualificação, com o propósito de contribuir para o desenvolvimento de competências institucionais, por meio do desenvolvimento de competências individuais".

As ações realizadas pela CCP ocorrem seguindo dois eixos: a participação do servidor em cursos de educação formal - internos ou externos à UFSC - e participação em eventos de aperfeiçoamento; os eventos restringem-se mais a jornadas, semanas científicas, simpósios, entre outros acontecimentos que envolvam palestras, workshops e demais atividades afins; já as ações de educação formal são aquelas oferecidas por sistemas formais de ensino, por instituições públicas ou privadas, enquadrando-se inclusive cursos de especialização latu e stricto sensu (UFSC, 2016c).

Destaca-se também que, desde 2013, os cursos têm seguido um caráter sistêmico de conhecimento, por meio de Programas Temáticos, "além de se apoiar nas perspectivas dos cargos e das funções exercidas pelos servidores, isto é, naquilo que é necessário e percebido, fundamenta-se nas diretrizes das linhas de desenvolvimento, previstas pelo Decreto 5.825, de junho de 2006" (UFSC, 2016c, p. 50-51). O referido Decreto diz respeito às diretrizes para elaboração do Plano de Desenvolvimento dos Integrantes do Plano de Carreira dos Cargos Técnico-Administrativos em Educação (Brasil, 2006b).

Por meio de pesquisa documental para verificar a ementa dos cursos, assim como entrevista não estruturada realizada com o Coordenador de Capacitações, foram analisadas as capacitações oferecidas pela UFSC, assim como a forma como os cursos são desenvolvidos e realizados, seus objetivos e resultados esperados com as capacitações. Após essa análise, foram elaborados as Tabelas 7, 8 e 9, que relacionam os três pilares constituintes das competências (conhecimentos, habilidades e atitudes) dos servidores aos cursos de capacitação disponibilizados pela CCP (UFSC, 2016c). As Figuras serão apresentadas em sequência com comentários ao final por se entender que a análise pode ser feita de forma conjunta. 
Tabela 7

Conhecimento exigido versus Capacitação disponível na UFSC

\begin{tabular}{lc}
\hline \multicolumn{1}{c}{ Conhecimento exigido } & Capacitação disponível \\
\hline - rotinas de cerimônias. & Cerimonial universitário. \\
\hline - perfil do público, suas necessidades, quantidade de pessoal e & \\
material necessários para o evento, fornecedores, cronograma & \\
de pedidos, equipe do evento, rotinas durante o evento, horários & \\
de entrega, entrega de becas, credenciamento dos participantes, \\
fotógrafos, documentos necessários, regulamento para profissio- \\
nais e empresas de fotografia e filmagem, portarias de Colação \\
de Grau emitidas pela PROGRAD anualmente.
\end{tabular}

- almoxarifado e material de expediente (materiais necessários, como solicitar o material, local de armazenamento).

- cuidados/manutenção dos materiais usados nas cerimônias (quais são os itens que atendem ao cerimonial universitário, como realizar a manutenção, quem realiza a manutenção).

- Resolução Normativa 31/CGRAD/2016.

- Licitação, gestão e fiscalização de contratos de projetos e obras de arquitetura e engenharia;

- controlar e acompanhar pregões e elaboração de termos de referência para licitações Lei 8.666 (1990), Lei 10.520 (2002), sistema de pregão eletrônico na UFSC, funcionamento das licitações na UFSC).

- Plataforma SOLAR: SPA, ALX e SCL;

- Mapeamento de processos administrativos;

- Instrução e acompanhamento de processos de compras na UFSC;

- Gestão e fiscalização de contratos terceirizados.

- Lei 4.320 (1964), contabilidade básica.

MATL-Sistema para gerenciar procedimentos administrativos relacionados aos centros de custo da UFSC.

- quais as atividades dos terceirizados, quais as responsabilidades dos terceirizados, quem são os prepostos.

- Gestão e fiscalização de contratos terceirizados.

- Páginas@UFSC, Repositório de Conte-

- gerenciar e atualizar o site (Wordpress). údo Digital (Dspace) e Galeria de Fotos (Gallery2).

- dispor de acesso à internet durante o evento.

- Português;

- Redação Oficial;

- secretaria de reunião;

- preenchimento de atas.

- Redação Oficial: Memorando, Ofício, Ata e Portaria

- Acordo Ortográfico e Revisão Gramatical;

- Mapeamento de processos administrativos.

Tabela 8

Habilidade exigida versus Capacitação disponível na UFSC

\begin{tabular}{ll}
\multicolumn{1}{c}{ Habilidade exigida } & \multicolumn{1}{c}{ Capacitação disponível } \\
\hline - usar equipamento de projeção; & - Informática Básica; \\
- manusear recursos de informática; & - Word para o Ambiente de Trabalho: Nível Básico; \\
- saber acessar a internet. & - Elaboração de Apresentações com PowerPoint e Prezzi; \\
& - Word para o Ambiente de Trabalho: Nível Avançado; \\
& - Excel para o Ambiente de Trabalho-Versão 20lO. \\
\hline - boa comunicação escrita. & - Redação Oficial: Memorando, Ofício, Ata e Portaria; \\
& - Acordo Ortográfico e Revisão Gramatical; \\
& - Leitura crítica e produção textual. \\
\hline
\end{tabular}




\begin{tabular}{ll}
\hline \multicolumn{1}{c}{ Habilidade exigida } & \multicolumn{1}{c}{ Capacitação disponível } \\
\hline - saber lidar com pessoas; & - Relações Interpessoais no Ambiente de Trabalho; \\
- boa comunicação verbal; & - Qualidade no Atendimento ao Cidadão. \\
- dar feedback. & - Planejamento Estratégico no Setor Público e UFSC; \\
\hline - liderança; & - Relações Interpessoais no Ambiente de Trabalho; \\
- delegação de tarefas; & - Mapeamento de processos administrativos. \\
- motivar equipe; & \\
- saber negociar; & \\
- planejamento; & \\
- organização. & \\
\hline - organização de ideias; & \\
- poder de síntese; & \\
- flexibilidade; & \\
- ser multitarefas. & \\
\hline - organização do espaço; & \\
- organização do temp; & \\
- manusear as becas. \\
\hline - ter facilidade com números; \\
- ter bom raciocínio; \\
- fazer cálculos.
\end{tabular}

Tabela 9

Atitude exigida versus Capacitação disponível na UFSC

\begin{tabular}{|c|c|}
\hline Atitude exigida & Capacitação disponível \\
\hline $\begin{array}{l}\text { - receptividade; } \\
\text { - simpatia; } \\
\text { - acolhimento; } \\
\text { - calma; } \\
\text { - paciência; } \\
\text { - gentileza; } \\
\text { - ser solícito; } \\
\text { - empatia com as pessoas; } \\
\text { - proatividade; } \\
\text { - controle. }\end{array}$ & $\begin{array}{l}\text { - Qualidade no atendimento ao cidadão; } \\
\text { - Relações interpessoais no ambiente de trabalho. }\end{array}$ \\
\hline \multicolumn{2}{|l|}{$\begin{array}{l}\text { - agilidade; } \\
\text { - concentração. }\end{array}$} \\
\hline - tomada de decisão. & - Planejamento Estratégico no Setor Público e UFSC. \\
\hline - ética profissional. & - Ética no Serviço Público. \\
\hline
\end{tabular}

Ao se refletir sobre as Tabelas 7, 8 e 9, pode-se observar que grande parte dos conhecimentos, habilidades e atitudes requeridas aos servidores ocupantes dos cargos de Administrador, Assistente em Administração e Auxiliar em Administração da UFSC é contemplada por capacitações que possuem, em seu conteúdo, aspectos que permeiam a sua essência. Entretanto, algumas das competências requeridas aos servidores carecem de capacitação, como pode ser observado na coluna da direita das Tabelas 7, 8 e 9, evidenciando uma lacuna (gap) entre o que se exige do ocupante do cargo e a disponibilidade de cursos que possam contribuir com a sua melhoria. 


\section{CONSIDERAÇÕES FINAIS}

Ao final do presente estudo pode-se observar que o seu objetivo inicial foi atingido, visto que foi evidenciado o relacionamento entre as capacitações oferecidas pela UFSC e as competências requeridas aos cargos de Administrador, Assistente em Administração e Auxiliar em Administração do seu Departamento de Cultura e Eventos. Por meio do estudo das atribuições legais e reais de cada cargo, foram identificadas e inventariadas as competências necessárias e, a partir dessa lacuna, elencados os conhecimentos, as habilidades e as atitudes que carecem de capacitação específica aos servidores.

Entende-se que os servidores lotados no DCEven/UFSC, ocupantes dos três cargos administrativos abrangidos por este estudo, têm, a seu dispor, diversas capacitações que podem incrementar o seu desempenho por meio do desenvolvimento de suas competências. Porém, essas mesmas capacitações ainda não são suficientes para abranger toda a necessidade dos servidores, haja vista a quantidade de conhecimentos, habilidades e atitudes que permanecem sem a devida capacitação, podendo resultar em um desempenho aquém do esperado. Algumas possibilidades de capacitação a serem implementadas podem ser elencadas para suprir os gaps encontrados, como capacitações relativas à organização de eventos, gestão de patrimônio, solicitações e cuidados com almoxarifado, gestão e manutenção de materiais usados em cerimônias de formatura, organização no ambiente de trabalho, entre outras que poderiam abranger as especificidades desse local de trabalho.

Após a pesquisa realizada, pode-se verificar a rigidez da administração pública ao adotar uma descrição de cargos que, por vezes, não é compatível com o trabalho realizado e resulta em problemas legais como desvio de função. Por fim, cabe ressaltar que não foi realizada uma pesquisa direta com os próprios servidores, buscando entender o seu ponto de vista. Tal fato, influenciado pelo movimento de greve dos servidores ali lotados, caracterizase como uma limitação ao estudo, visto que impossibilitou uma maior profundidade de análise. Desse modo, sugere-se a realização de estudos futuros sobre o tema, especialmente no que se refere às competências dos servidores, permitindo investigá-lo de maneira ainda mais profunda, apurando outras possíveis capacitações que hoje não existem, com o intuito de desenvolver ainda mais os servidores desse Departamento para a realização das suas atividades práticas.

\section{REFERÊNCIAS}

Amaral, R. M. do. (2008). Gestão de pessoas por competências em Organizações públicas. Anais do Seminário Nacional de Bibliotecas Universitárias, São Paulo, 15. 
Bateman, T. S., \& Snell, S. (2011). Administração: Novo cenário competitivo. (2a ed.). São Paulo: Atlas.

Belfort, R. M, Santos, Eliana di F. M. da S., \& Tadeucci, M. de S. R. (2012, Janeiro/Julho). Gestão por competências: Um novo modelo de gerenciamento. Revista UNI, 2, 39-53.

Cervo, A. L., \& Bervian, P. A. (1983). Metodologia Científica. (3a ed.). São Paulo: McGraw-Hill do Brasil.

Cervo, A. L., Bervian, P. A., \& Silva, R. da. (2007). Metodologia científica. (6a ed.). São Paulo: Pearson Prentice Hall.

Dalmau, M. B. L. (2014). Competências gerenciais requeridas aos gestores de nível intermediário nas Instituições Federais de Ensino de Santa Catarina. Florianópolis: Capes.

Decreto 5.707, 2006a. Recuperado de www.planalto.gov.br/ccivil_03/_Ato2004-2006/2006/ Decreto/D5707.htm

Decreto 5.825, 2006b. Recuperado de www.planalto.gov.br

Dutra, J. S. (2001). Gestão por competências: Um modelo avançado para o gerenciamento de pessoas. São Paulo: Gente.

Eco, U. (2014). Por que as Universidades? Recuperado de http://marcoanogueira.blogspot. com.br/2014/06/umberto-eco-por-que-as-universidades.html

Fleury, M. T. L., \& Fleury, A. (2001). Desenvolver competências e gerir conhecimentos em diferentes arranjos empresariais: $\mathrm{O}$ caso da indústria brasileira de plástico. In M. T. L. FIeury, M. T. L. J. Oliveira, \& M. de Miranda (Orgs.). Gestão estratégica do conhecimento: Integrando aprendizagem, conhecimento e competências. (pp.189-211). São Paulo: Atlas.

Gil, A. C. (2007). Como elaborar projetos de pesquisa. (4a ed.). São Paulo: Atlas.

Gil, A. C. (2010). Como elaborar projetos de pesquisa. (5 ed.). São Paulo: Atlas.

Gomes, C. E. (2008). Competências organizacionais e individuais: $O$ que são e como se desenvolvem. In A. S. Godoy, D. M. M. Hanahsiro, M. L. M. Teixeira, \& L. M. Zaccarelli. Gestão do fator humano: Uma visão baseada nos stakeholders. (2 ${ }^{a}$ ed.). (pp. 217-257). São Paulo: Saraiva. 
Grillo, A. N. (2001). Gestão de pessoas: Princípios que mudam a administração universitária. Florianópolis: UFSC/CAD.

Kwasnicka, E. L. (2007). Introdução a administração. (6 ed.). São Paulo: Atlas.

Lei 11.09l, 2005. Recuperado de http://www.planalto.gov.br/ccivil_03/_ato2004-2006/2005/ lei/Ll109lcompilado.htm

Minayo, M. C. de S. (Org.). (2001). Pesquisa social: Teoria, método e criatividade. (19a ed.). Petrópolis: Vozes.

Moraes, A. M. P. de. (2004). Introdução à Administração. (3a ed.). São Paulo: Prentice Hall.

Moura, D. L. de. (2009). Competências Requeridas no Mercado Globalizado. In Fischer, A. L., Dutra, J. S., \& Amorim, W. A. C. de. (Org.). Gestão de Pessoas: Desafios Estratégicos das Organizações Contemporâneas. (pp. 77-98). São Paulo: Atlas.

Ofício Circular 015/2005/CGGP/SAA/SE/MEC, 2005. Recuperado de http://portal.mec.gov. $\mathrm{br} /$ arquivos/pdf/canalcggp/oficios/oc01505.pdf

Robbins, S. P. (2000). Administração: Mudanças e perspectivas. São Paulo: Saraiva.

Roesch, S. M. A. (2012). Projetos de estágio e de pesquisa em administração: Guia para estágios, trabalhos de conclusão, dissertações e estudos de caso. ( $3^{a}$ ed.). São Paulo: Atlas.

Ruiz, João Álvaro (2002). Metodologia científica: Guia para eficiência nos estudos. ( $5^{a}$ ed.). São Paulo: Atlas.

Santos, I. E. dos. (2010). Manual de métodos e técnicas de pesquisa científica. Niterói: Impetus.

Sartoretto, M. de F. A. T. (2016). Competências gerenciais: Um estudo na Universidade Federal da Fronteira Sul (Trabalho de Conclusão de Curso de bacharelado). Universidade Federal da Fronteira Sul, Chapecó.

Snell, S., \& Bohlander, G. (2009). Administração de recursos humanos. São Paulo: Cengage Learning.

Torres, A. A., Ziviani, F., Silva, S. M. (2012, Setembro/Dezembro). Mapeamento de competências: Ferramenta para a comunicação e a divulgação científica. TransInformação, 191-205. Recuperado de http://www.scielo.br/pdf/tinf/v24n3/a04v24n3.pdf 
Tosta, H. T. (2011). Competências gerenciais requeridas aos gestores intermediários da Universidade Federal da Fronteira Sul (Dissertação de mestrado). Universidade Federal de Santa Catarina, Florianópolis.

Universidade Federal de Santa Catarina. (2016a). A SecArte. Recuperado de http://secarte. ufsc.br/apresentacao

Universidade Federal de Santa Catarina. (2016b). Estrutura UFSC. Recuperado de http:// estrutura.ufsc.br

Universidade Federal de Santa Catarina. (2016c). Plano Anual de Capacitação. Florianópolis: UFSC. Recuperado de http://capacitacao.ufsc.br/Pac2016.html

Universidade Federal de Santa Catarina. (2016d). Regimento Interno da Secretaria de Cultura da Universidade Federal de Santa Catarina. Florianópolis: UFSC. Recuperado de http://secarte.paginas.ufsc.br/files/2016/01/Regimento-Interno-publicar.pdf

\section{Como citar este artigo:}

\section{ABNT}

MENDES, Monica Scoz et al. Mapeamento e desenvolvimento de competências: um estudo de caso nos cargos administrativos do Departamento de Cultura e Eventos da UFSC.

RACE, Revista de Administração, Contabilidade e Economia, Joaçaba: Editora Unoesc, v. 18, n. 2, p. 299-320, maio/ago. 2019. Disponível em: http://editora.unoesc.edu.br/index.php/ race. Acesso em: dia/mês/ano.

\section{APA}

Mendes, M. S., Souza, G. M. de, Tosta, K. C. B. T., \& Dalmau, M. B. L.

(2019). Mapeamento e desenvolvimento de competências: um estudo de caso nos cargos administrativos do Departamento de Cultura e Eventos da UFSC. RACE, Revista de Administração, Contabilidade e Economia, 18(2), 299-320. Recuperado de http://editora. unoesc.edu.br/index.php/race 
